\title{
Exothermic Reaction Induced Eutectic Pb-Sn Solder Ball Melting in the Underfill Curing Process
}

\author{
Woon-Seong Kwon, Se-Young Jang, and Kyung-Wook Paik, Member, IEEE
}

\begin{abstract}
The effects of exothermic heat generated during underfill curing on the integrity of the solder bumped package, which is an important issue for the package reliability, have been overlooked. In this study, theoretical exotherm of underfill materials during underfill curing has been calculated using a differential scanning calorimeter (DSC) at cure temperature range from $100{ }^{\circ} \mathrm{C}$ to $200{ }^{\circ} \mathrm{C}$. The calculated exotherm was compared with the exotherm profile measured at the typical cure temperature. The effects of cure temperature, amount of underfill, and initial underfill curing temperature on the exotherm profile of underfill materials have been investigated.
\end{abstract}

Index Terms_Exotherm, flip chip, solder ball melting, underfill.

\section{INTRODUCTION}

$\mathbf{F}$ OR SOLDER flip chip interconnection, it is necessary to use underfill materials to improve the package reliability [1]-[4]. During the underfill cure, exothermic reaction is generated due to the energy release by the curing reaction of the epoxy groups. In the curing reaction of underfills, the heat, if liberated during a short period of time, will result in a substantial increase of temperature at underfill area. This temperature increase, which is measured by a thermocouple, is referred to as exotherm [5]. Until now, this exotherm phenomenon during the underfill curing was overlooked during flip chip assembly process.

In our test-vehicle, eutectic $\mathrm{Pb}-\mathrm{Sn}$ solder ball melting phenomena were observed during the underfill curing at $165^{\circ} \mathrm{C}$ for $30 \mathrm{~min}$. It is considered that this unexpected solder ball remelting phenomenon is due to the high exotherm during underfill curing. The real package with the good heat dissipation may effectively distribute the exothermic heat during the underfill cure process into the outside of the package, but nevertheless instantaneous exothermic heat at the early stage of crosslinking reaction can potentially deteriorate the functional devices on the active surface of package. Accordingly, the fundamental understanding of exothermic reaction during underfill curewill provide the solution to avoid the high peak exotherm by optimizing

\footnotetext{
Manuscript received February 1, 2003; revised July 30, 2003. This work was supported in part by the Center for Electronic Packaging Materials, Korea Science and Engineering Foundation. This work was recommended for publication by Associate Editor C. C. Lee upon evaluation of the reviewers' comments.

W.-S. Kwon and K.-W. Paik are with the Department of Materials Science and Engineering, Korea Advanced Institute of Science and Technology (KAIST), Daejon 305-701, Korea (e-mail: wskwon@ @ais.kaist.ac.kr).

S.-Y. Jang is with the Department of Materials Science and Engineering, Korea Advanced Institute of Science and Technology (KAIST), Daejon 305-701, Korea, and also with the Samsung Electronics Company, Ltd., Gyeonggi-do, Korea (e-mail: seyoung.jang@ @amsung.com).

Digital Object Identifier 10.1109/TCAPT.2004.825753
}

the underfill cure conditions such as underfill amount and curing temperature.

The objective of this study is to investigate the exothermic reaction effect during underfill curing process. In particular, discussion will be focused on the effect of underfill cure variables on underfill exotherm during the underfill cure.

\section{Eutectic Pb-Sn Solder Ball Melting During UNDERFILL CURING}

Test-vehicles were Duroid organic substrates which originally fabricated to investigate the high frequency behavior of flip chip structure with eutectic $\mathrm{Pb}-\mathrm{Sn}$ solder ball. Schematic figure of test vehicle was shown in Fig. 1. The Duroid test-vehicle structure consists of solder ball with various ball pitches and ground vias as shown in Fig. 1. After the solder ball (300, 500 , and $760 \mu \mathrm{m}$ in diameter) attachment on pads of bottom test-vehicles and the flip chip bonding on the other substrate, the cure process of commercial underfill was performed at $165^{\circ} \mathrm{C}$ for $30 \mathrm{~min}$, which was supplied by vendor as shown in Table I. This situation of organic PCB package solder-ball interconnected on another organic substrate is similar as the plastic BGA packages assembled on organic board using underfill between them. Typical BGA and CSP packages are assembled on organic substrate such as FR-4 board using underfill material to increase drop shock reliability. Unexpectedly, some small solder balls were found on the top side of test-vehicle after underfill curing as shown in Fig. 2. It is found that solder ball remelting occurs during the progress of underfill cure, and the remelted solder climbs up through the ground via close to solder ball pad. Accordingly, one can imagine that the exothermic reaction of underfill material during the cure process results in the temperature rise over eutectic $\mathrm{Pb}-\mathrm{Sn}$ solder ball meting temperature, $183^{\circ} \mathrm{C}$.

\section{Calculation of Exotherm Due to The UNDERFILL CURE}

The temperature rise experienced by the exothermic reaction during underfill curing can be expressed by

$$
\Delta H\left(\frac{J}{g}\right)=C_{p}\left(\frac{J}{g \times{ }^{\circ} \mathrm{C}}\right) \times \Delta T\left({ }^{\circ} \mathrm{C}\right) .
$$

In this expression, heat of reaction $(\Delta H)$ and specific heat $\left(C_{p}\right)$ were experimentally determined by a differential scanning calorimeter (Perkin-Elmer DSC-7) equipped with DSC-7 kinetics software over a temperature range from 50 to $200{ }^{\circ} \mathrm{C}$ with a heating rate of $10{ }^{\circ} \mathrm{C} / \mathrm{min}$. The underfill samples 


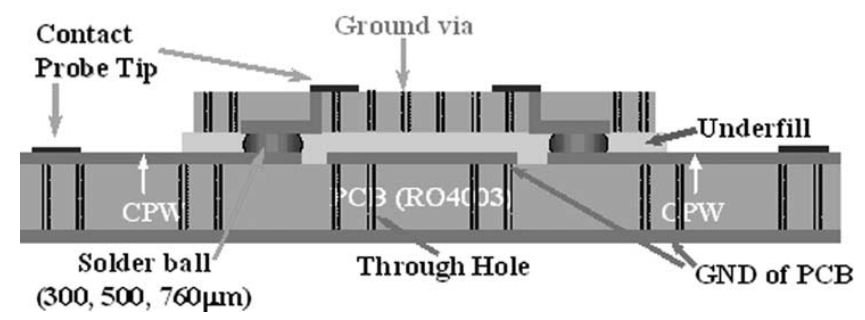

Fig. 1. Schematics of test-vehicle consisting of solder balls and ground vias.

TABLE I

SOME PROPERTIES OF UNDERFILL MATERIAL SUPPLIED By VENDOR

\begin{tabular}{lccc} 
& & \multicolumn{2}{c}{ Supplied by underfill vendor } \\
\hline Material & $\begin{array}{c}\text { Dispensing } \\
\text { temperature }\end{array}$ & Cure schedule & Filler content \\
\hline Underfill & $90^{\circ} \mathrm{C}$ & 30 min @ $165^{\circ} \mathrm{C}$ & $50 \%$ \\
\hline
\end{tabular}

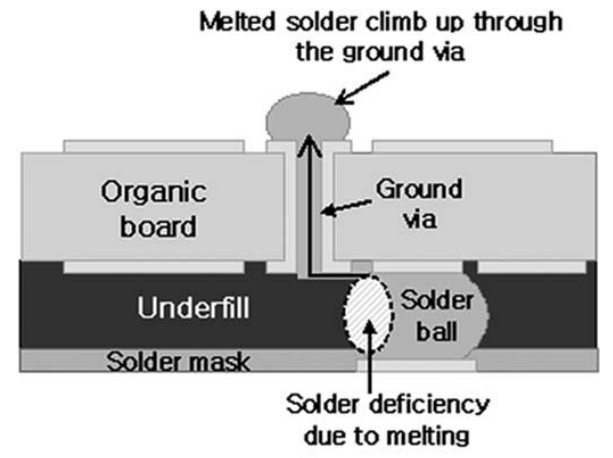

(a)

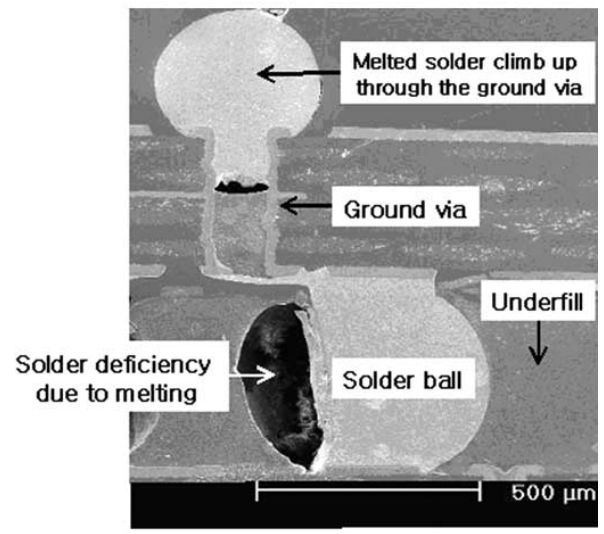

(b)

Fig. 2. (a) Schematic picture and (b) SEM photograph of eutectic $\mathrm{Pb}-\mathrm{Sn}$ solder ball melting phenomena after underfill curing process.

(50 wt $\%$ silica filler) were poured into an aluminum cup, and then weighed before the introduction into the DSC. $\mathrm{N}_{2}$ gas was continuously purged into the sample chamber to prevent any possibility of oxidation. The total heat of reaction $\left(\Delta H_{\text {total }}\right)$ of underfill including silica filler was estimated by drawing a line connecting the baseline before and after the exothermic peak and then integrating the enclosed area. Assume that the heat curing systems (epoxy-based resin + curing agent) occupy $50 \mathrm{wt} \%$ fraction in the underfill compound because underfill is filled with $50 \mathrm{wt} \%$ silica filler. Therefore, the heat of curing

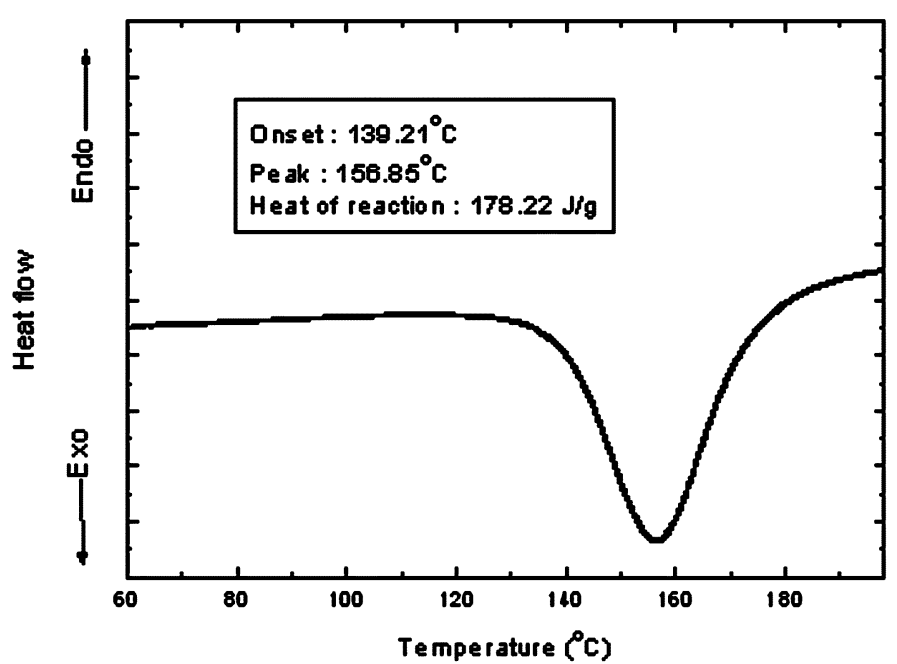

(a)

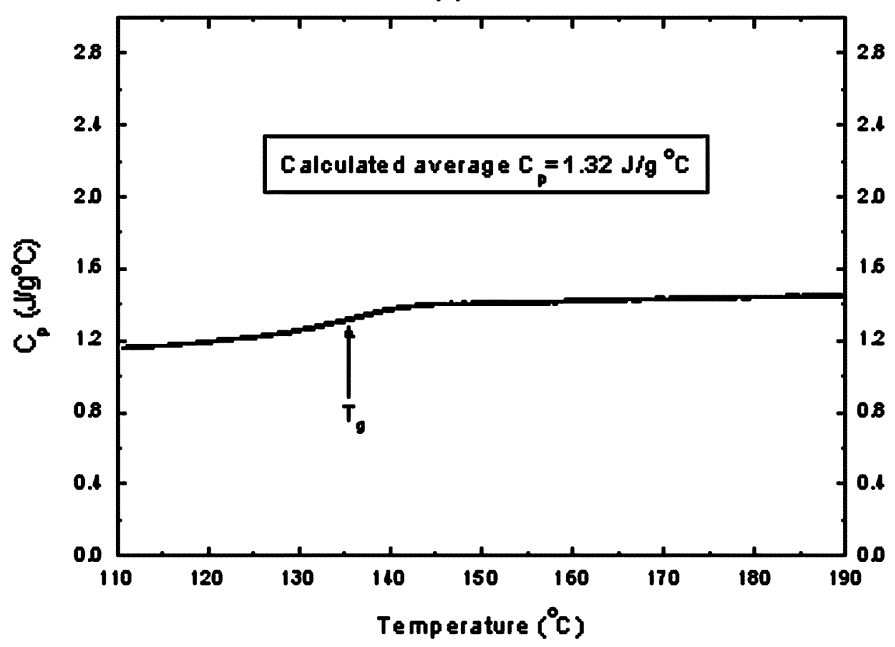

(b)

Fig. 3. DSC scan results of underfill material. (a) DSC dynamic scan of underfill materials. (b) Specific heat of cured underfill materials.

reaction $(\Delta H)$ for underfill materials should be calculated by dividing the total heat of reaction $\left(\Delta H_{\text {total }}\right)$ by 0.5 . Based on the DSC dynamic scan of cured underfill and blank sample, the specific heat $\left(C_{p}\right)$ was calculated using DSC-7 kinetics software. A blank run was made of the every measurement of the specimens. Fig. 3(a) and (b) show the dynamic scan and $C_{p}$ measurement results for the exotherm calculation of the underfill material respectively. From these measurements, we have obtained $\Delta H$ is $178.22 \mathrm{~J} / \mathrm{g}$ and $C_{p}$ is $1.32 \mathrm{~J} / \mathrm{g}^{\circ} \mathrm{C}$ for the tested underfill material. The calculation result based on (1) for the exotherm of the underfill material is described as

$$
\begin{aligned}
\Delta H\left(\frac{J}{g}\right) & =C_{p}\left(\frac{J}{g^{\circ} \mathrm{C}}\right) \times \Delta T\left({ }^{\circ} \mathrm{C}\right) \\
\frac{178.22}{0.5}\left(\frac{J}{g}\right) & =1.32\left(\frac{J}{g^{\circ} \mathrm{C}}\right) \times \Delta T \quad \therefore \Delta T=270.03^{\circ} \mathrm{C} .
\end{aligned}
$$

This is indicative of the total heat given off during the underfill cure and is a large temperature rise enough to remelt the eutectic $\mathrm{Pb}-\mathrm{Sn}$ solder ball. This calculated temperature rise due to exotherm, of course, would represent the adiabatic temperature rise that would be experienced only if the underfill is reacted in 


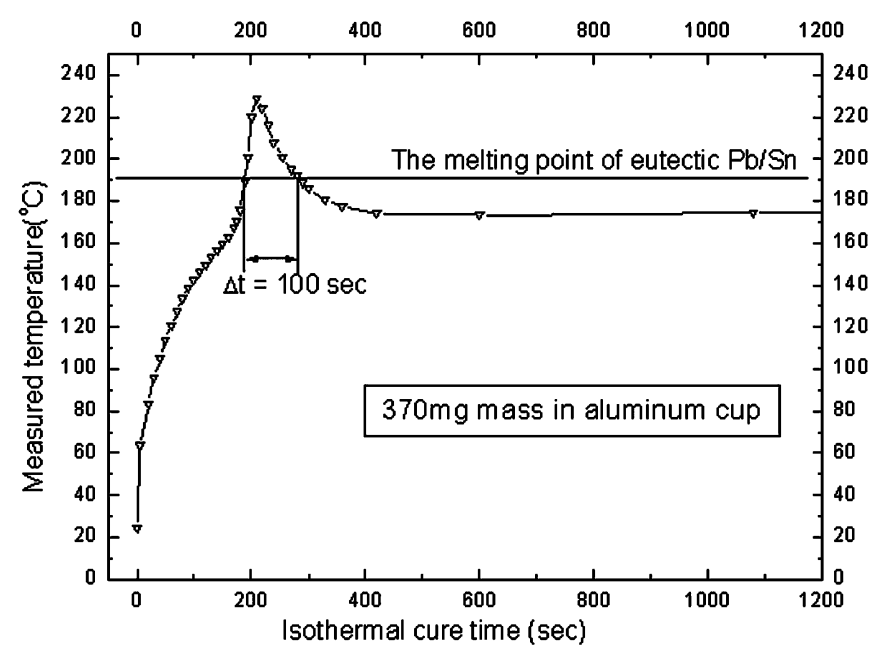

Fig. 4. The typical exotherm profile of underfill materials cured at $165^{\circ} \mathrm{C}$ oven temperature. Test runs were made with $370-\mathrm{mg}$ underfill material.

a perfectly insulated container. In actual assembly, however, the underfill is continuously losing heat to the surroundings such as silicon chips, substrates, and the air. In addition, the specific heat probably increases gradually as the temperature rises, further tending to limit the temperature finally reached. The measured exotherm profile of the underfill material at $165^{\circ} \mathrm{C}$ oven temperature is shown in Fig. 4. The temperature was measured by inserting a thermocouple wire in the underfill material. The peak exotherm reach almost $230{ }^{\circ} \mathrm{C}$ after $200 \mathrm{~s}$, and it is held about $100 \mathrm{~s}$ above the melting point of eutectic $\mathrm{Pb}-\mathrm{Sn}$ solder. Accordingly, even though the cure reaction of underfills in this experiment does not experience an adiabatic exotherm, some detrimental effects, such as remelting of solder, can be experienced by this high exotherm.

One of the reasons for high exotherm in this case is because of the thermal conductivity of organic package substrate flip chip assembled on another organic substrate is quite low. However, this case is quite similar as BGA or CSP packages using organic interposer with solder balls assembled on organic board for the cellular phone applications.

\section{IN-Situ ElECtRICAL RESISTANCE MEASUREMENT OF EUTECTIC Pb-Sn SOLDER INTERCONNECTS DURING UNDERFILL CURING}

The resistance changes of eutectic $\mathrm{Pb}-\mathrm{Sn}$ solder ball interconnect were monitored during underfill cure. The Asymtek Flip-Chip Calculator software was used to determine the exact amount of underfill materials. The calculated underfill amount for test-device is $113.67 \mathrm{mg}$. Flip chip assembly before and after the underfill dispensing were weighed. As a result, the actual underfill amount was about $102 \mathrm{mg}$. Fig. 5 shows the monitored results of resistance change during the underfill cure.

To investigate the effect of high exotherm during underfill curing on the in-situ electrical resistance change, electrical resistances of solder balls without and with underfill materials were measured under the $165^{\circ} \mathrm{C}$ cure temperature profile, respectively. Fig. 5 shows the electrical resistance changes of eutectic $\mathrm{Pb}-\mathrm{Sn}$ solder interconnects without and with underfill materials.

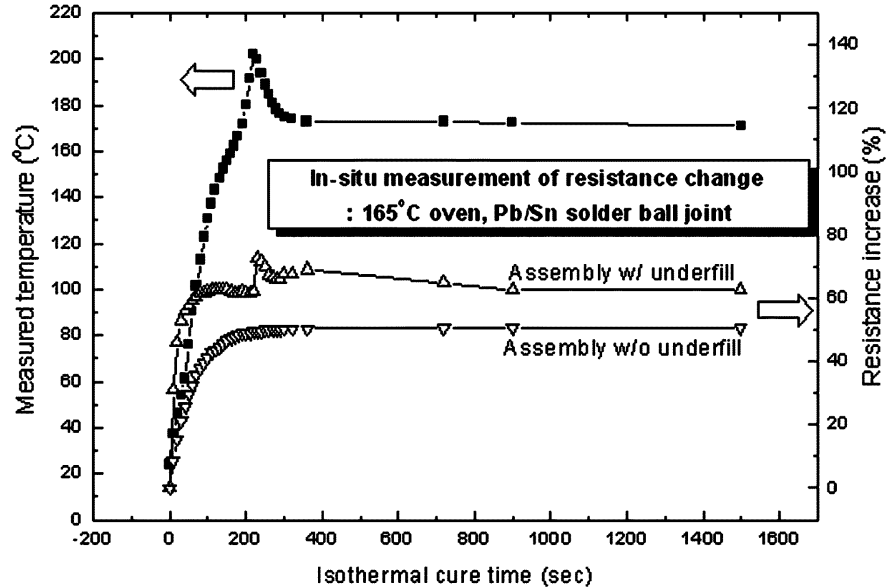

Fig. 5. In-situ measurement results of electrical resistance changes of eutectic $\mathrm{Pb}-\mathrm{Sn}$ solder bump joint. (a) Resistance change without and with underfill materials. (b) Underfill exotherm and joint electrical resistance changes during underfill curing at $165^{\circ} \mathrm{C}$ oven.

In the assembly with underfill materials, the abrupt electrical resistance increase was observed. And abrupt resistance increase peak was exactly corresponded to the peak exotherm position of the temperature profile as shown in Fig. 5. This abrupt electrical resistance increase could be originated from either the temperature increase or solder joint remelting. In practice, however, it is difficult to distinguish these two issues experimentally, since both of them contribute to the resistance increase during the underfill cure. On the other hand, joint electrical resistance after underfill cure process showed 15-20\% increase when compared with that of the assembly before underfill cure. Therefore, it is expected that this increase in electrical resistance is originated from detrimental effects such as solder remelting or intermetallic compound formation during underfill curing.

\section{EFFects of VARious Cure Conditions on EXOTHERM PROFILE}

The underfill sample (50 wt\% silica filler) was poured into an aluminum cup, and then weighed before introducing into a curing oven. And a thermo-couple was plugged into the poured underfill material for the exact measurement of exotherm profile during curing. Curing oven temperature was held at target temperatures of $125^{\circ} \mathrm{C}, 145^{\circ} \mathrm{C}$, and $165^{\circ} \mathrm{C}$ within $\pm 5^{\circ} \mathrm{C}$.

\section{A. Effect of Curing Temperature on Exotherm Profile}

Underfill curing at elevated temperature has an advantage of obtaining higher degree of cure for a shorter time. However, with the consideration of exothermic phenomena of underfill curing, curing temperature must be carefully selected.

Fig. 6 shows the effect of oven curing temperatures on peak exotherm of underfill curing. With increasing curing oven temperature, peak exotherm increases, and time to reach the peak temperature decreases. In other words, curing becomes faster at higher curing temperature. If the underfills are cured at higher temperature to obtain high degree of cure for a short period of time, then more amounts of exothermic heat were generated during shorter curing time resulting in a higher temperature rise and less time for heat dissipation to surrounding. Accordingly, 


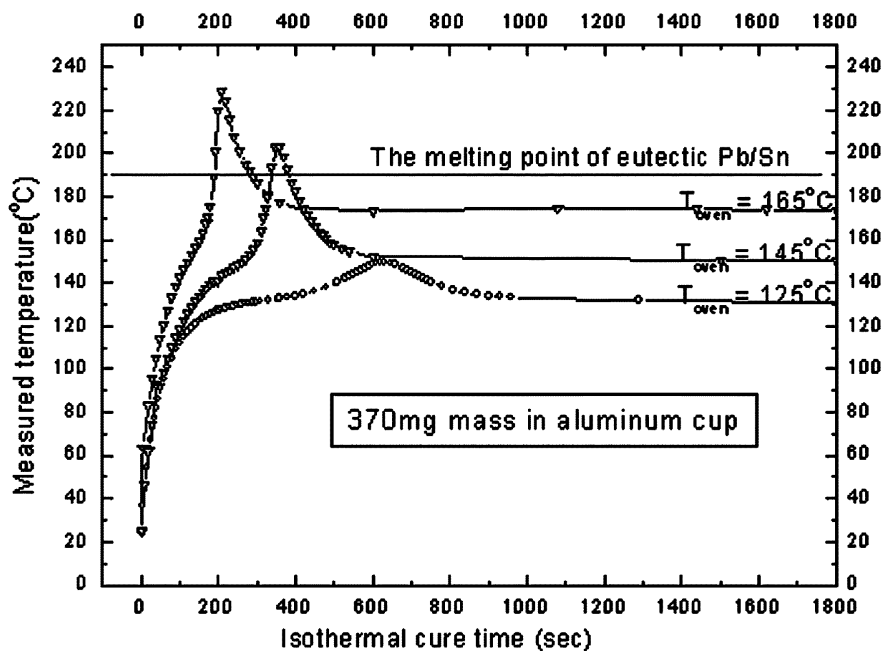

Fig. 6. Effect of curing oven temperature on peak exotherm of $370 \mathrm{mg}$ of underfill materials measured in aluminum cups.

temperature rises as an adiabatic condition. If using a very fast cure underfill material called "snap cure," it can be quite possible for the center of underfills to reach temperature rise as a theoretical adiabatic condition. Therefore, higher peak exotherm at higher curing temperature can lead to detrimental phenomena such as eutectic $\mathrm{Pb}-\mathrm{Sn}$ solder ball remelting or additional intermetallic compound formation. To avoid these effects due to higher peak exotherm, it is necessary for the underfill materials to be cured at lower temperature to dissipate the heat for a longer period time. However, lower underfill curing temperature causes longer curing times to reach the ultimate degree of cure. Therefore curing temperature should be carefully optimized.

\section{B. Effect of Underfill Amount on Exotherm Profile}

From BGA/CSP to flip chip packages, the required underfill amount is dependent upon the die size, fillet size, solder bump diameter, solder bump height, and number of bumps (I/O).

Fig. 7 shows the effect of the underfill amount on exotherm profile at $165{ }^{\circ} \mathrm{C}$ curing oven temperature. When large amount of underfill was cured, peak exotherm decreased with decreasing the cure temperature. In the meanwhile, when underfill was cured at high cure temperature $\left(165^{\circ} \mathrm{C}\right)$, peak exotherm decreased with decreasing the underfill amount. This is due to total amount heat generated become less with smaller amount of underfill material. In viewpoint of thermal conductivity, when curing large amount of underfill materials, the exothermic heat at the center cannot be effectively transferred to the outer environment presumably resulting in a higher temperature than the surrounding temperature. As mentioned above, if using a large amount of snap cure, the center of underfills possibly reaches quite high temperature approaching theoretical adiabatic. In the real flip chip assembly, the underfill amount required for flip chip application is small and the heat conduction through the $\mathrm{Si}$ chip is efficient, therefore, detrimental effects such as eutectic $\mathrm{Pb}-\mathrm{Sn}$ solder remelting can be reduced. However, in case of CSP or BGA packages assembled on another organic board, high exotherm can be

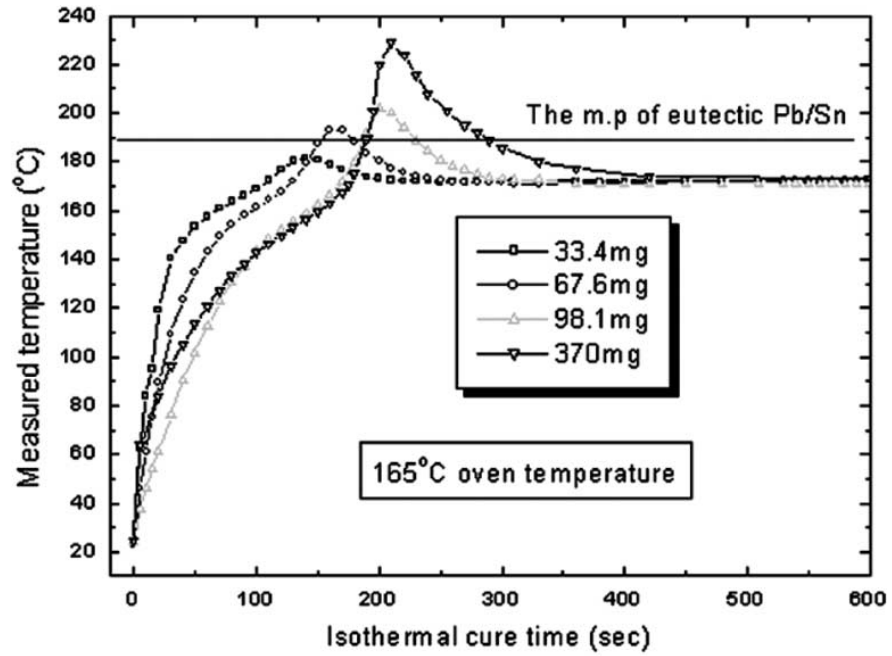

Fig. 7. Effect of underfill amount on peak exotherm cured at $165{ }^{\circ} \mathrm{C}$ oven temperature.

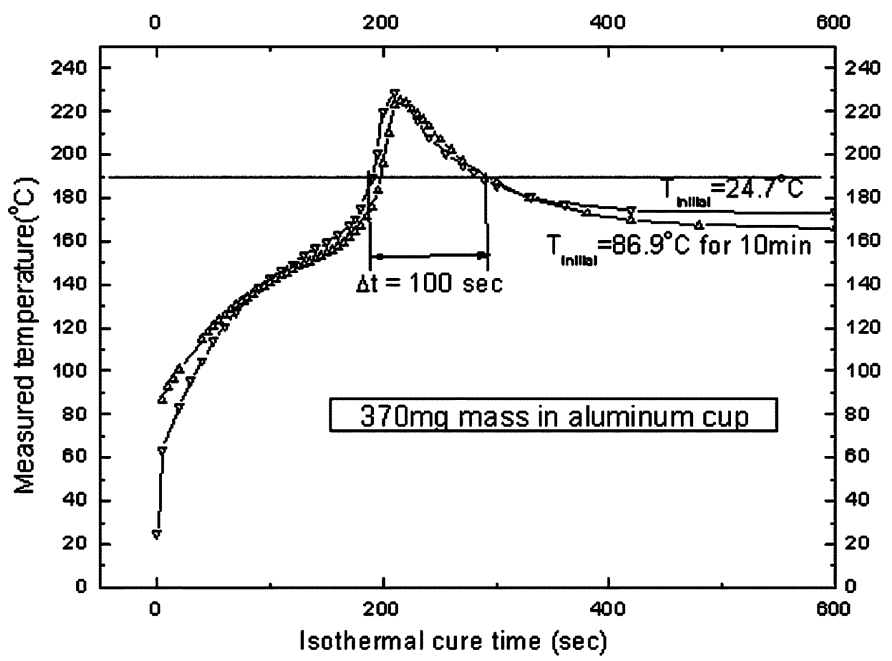

Fig. 8. Effect of initial underfill dispensing temperature on peak exotherm of $370 \mathrm{mg}$ of underfill materials.

occurred due to the large amount of underfill materials and poor thermal conductivity of organic interposers of CSP and BGA packages. Therefore, it is necessary to optimize curing condition, such as curing temperature, underfill amount, and proper geometry design.

\section{Effect of Initial Underfill Dispensing Temperature on Exotherm Profile}

In general, underfills are dispensed on $80 \sim 90^{\circ} \mathrm{C}$ heating stage to lower the underfill viscosity and so enable them to wet the various surfaces and subsequently flow under the flip chip device. It is necessary to investigate the effect of preheating on the exothermic reaction. In this experiment, underfills were heated for $10 \mathrm{~min}$ in an oven of $90^{\circ} \mathrm{C}$ and then moved to $165^{\circ} \mathrm{C}$ cure oven.

Fig. 8 shows the effect of initial underfill dispensing temperature on exotherm profile of $370 \mathrm{mg}$ of underfill materials. Exotherm profile was not affected by initial underfill dispensing temperature, because curing reaction does not start at $86.9^{\circ} \mathrm{C}$. 


\section{CONCLUSION}

In our test-devices of organic substrate interposers assembled on another organic substrate with solder bump joint and underfill materials, eutectic $\mathrm{Pb}-\mathrm{Sn}$ solder ball remelting phenomena were observed during the underfill curing, because of exothermic reaction of underfill curing. Solder ball remelting is not desirable in reliability view. In this study theoretical exotherm of underfill materials during underfill curing was calculated, and the various effects of underfill curing conditions on the exotherm profile of underfill materials were investigated. At higher underfill cure temperature, peak exotherms increase and approach almost the calculated value under adiabatic conditions. When curing smaller amount of underfill at the same curing temperature $\left(165^{\circ} \mathrm{C}\right)$, peak exotherm was significantly lowered than that of larger amount of underfill because of less exothermic heat generation and good dissipation. Exothermic profile was not affected by initial underfill dispensing temperature. In flip chip assembled samples with underfill, the abrupt electrical resistance increase was observed during isothermal underfill curing. And it was exactly corresponded to the peak exotherm of the temperature profile. As a summary, abrupt electrical resistance increase is due to detrimental effects such as solder remelting or intermetallic compound formation during underfill curing. It is recommended that underfill curing parameters such as curing temperature, underfill amount, and flip chip assembly geometry, should be properly optimized to prevent unexpected overheating during underfill curing.

\section{REFERENCES}

[1] K. Darbha, J. H. Okura, S. Shetty, A. Dasgupta, T. Reinikainen, J. Zhu, and J. F. Caers, "Thermomechanical durability analysis of flip chip solder interconnects: part 2-with underfill," J. Electron. Packag., vol. 121, pp. 237-241, Nov. 1999.

[2] P. L. Tu, Y. C. Chan, and K. C. Hung, "Reliability of microBGA assembly using no-flow underfill," Microelectron. Reliab., vol. 41, no. 12, pp. 1993-2000, 2001.

[3] V. Gektin, A. Bar-cohen, and J. Ames, "Coffin-manson fatigue model of underfilled flip-chips," IEEE Trans. Comp., Packag., Manufact. Technol. A, vol. 20, pp. 317-326, Sept. 1997.

[4] B. Roesner, "The beneficial effect of underfilling on the reliability of flip-chip joints," Solder Surface Mount Technol., vol. 10, no. 2, pp. 14-18, 1998.

[5] H. Lee and K. Neville, Handbook of Epoxy Resins. New York: Mcgraw-Hill, 1982.

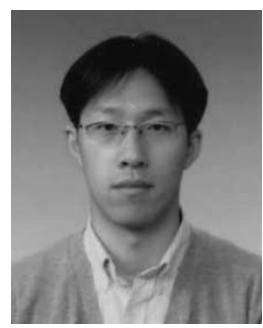

Woon-Seong Kwon received the B.S. and M.S. degrees in material science and engineering from the Korea Advanced Institute of Science and Technology (KAIST), Daejon, in 1998 and 2001, respectively, where he is currently pursuing the Ph.D. degree in microelectronic packaging.

His research interests are the development of anisotropic conductive adhesive materials for packaging application, flip-chip using polymeric adhesive and its reliability assessment, and high frequency electrical characterization.

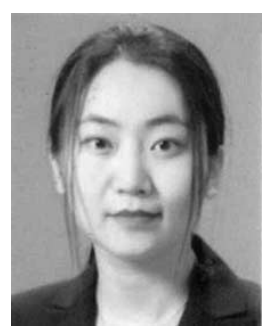

Se-Young Jang received the B.S., M.S., and Ph.D. degrees in materials science and engineering from the Korea Advanced Institute of Science and Technology (KAIST), Daejon, in 1996, 1998, and 2002, respectively.

From October 1996 to December 1997, she had worked on the characterization of flip chip bonding process in the internship program at Motorola, Korea. In 1999, she visited the Fraunhofer IZM, Germany, within a DAAD student exchange program. From April 2000 to April 2001, she worked in the Department of High Density Interconnect and Wafer Level Packaging, Fraunhofer IZM, as a Visiting Researcher and developed Pb-free SnAg electroplated bumping process. Since September 2002, she has been with Samsung Electronics Company, Ltd., Gyeonggi-do, Korea, as a Senior Engineer. Her current research interests are flip chip applications, $\mathrm{Pb}$-free assembly, and system-in-package.

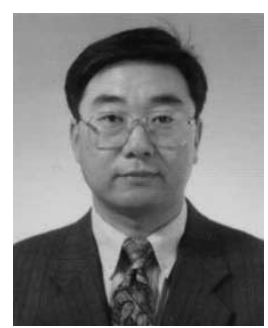

Kyung-Wook Paik (M'95) received the B.Sc. degree in metallurgical engineering from Seoul National University, Seoul, Korea, in 1979, the M.Sc. degree from the Korea Advanced Institute of Science and Technology (KAIST), Taejon, in 1981, and the Ph.D. degree in materials science and engineering from Cornell University, Ithaca, NY, in 1989.

From 1982 to 1985 , he was with KAIST, Seoul, Korea, as a Research Scientist and was responsible for various materials development such as gold bonding wire and nonferrous alloys. After the Ph.D. degree, he worked at the General Electric Corporate Research and Development from 1989 to 1995 , where he was involved with the R\&D of materials and processes of GE High Density Interconnect (HDI) multichip module technology and power I/C packaging as a Senior Technical Staff. Since joining KAIST in 1995, he has been with the Department of Materials Science and Engineering as an Associate Professor. He is currently working in the area of MCM, flip-chip, MEMS, and display packaging. He visited the Packaging Research Center, Georgia Institute of Technology, Atlanta, as a Visiting Professor from March 1999 to February 2000, and was involved in the educational and integrated passives research programs. He has published more than 60 technical papers in the area of electronic packaging and currently holds 14 U.S. patents with four U.S. patents pending.

Dr. Paik is the chairman of Korean IEEE-CPMT chapter and a Member of IMAPS. 